\title{
Research on the Protection and Renewal of Nanjing Industrial Heritage from the Perspective of Urban Regeneration
}

\author{
Jingjing $\mathrm{Xu}^{1, *}$ Lei Jiang ${ }^{2}$ Junjin Qian ${ }^{3}$ \\ ${ }^{1}$ NanJing XiaoZhuang University, Nanjing, Jiangsu, China \\ ${ }^{2}$ Nanjing Tech University, Nanjing, Jiangsu, China \\ ${ }^{3}$ Zhejiang Hongtu Architectural Design Co., Ltd., Hangzhou, Zhejiang, China \\ *Corresponding author. Email: art.xujingjing@163.com
}

\begin{abstract}
Through sorting out and analyzing the background of the formation of Nanjing modern industrial heritage, this article analyzes the characteristics of Nanjing's modern industrial heritage from historical characteristics, spatial distribution characteristics and type characteristics, and expounds four coupling modes between the protection and renewal of Nanjing's industrial heritage and urban regeneration. On this basis, it puts forward countermeasures and suggestions on how to make sustainable use of industrial heritage against the background of urban regeneration as well as the protection and renewal of industrial heritage.
\end{abstract}

Keywords: Urban regeneration, Nanjing industrial heritage, Protection and renewal.

\section{INTRODUCTION}

Nanjing is one of the birthplaces of modern Chinese industry. As a new type of cultural heritage, the city's industrial heritage has witnessed the process of China's industrialization and modernization, and recorded the industrial development process of the modern Westernization Movement of "learning from foreigners to compete with them", "improving themselves", and "seeking wealth", carrying the precious memories of a generation. The cultural connotation contained in the city's industrial heritage enriches the multicultural experience and spatial awareness of the city, and the protection and renewal of industrial heritage is of great significance to the inheritance and rejuvenation of urban cultural heritage, as well as the transformation and innovative development of urban industries.

*Funds: Phased research results of the Jiangsu University Philosophy and Social Science Research Project "Investigation and Practice of Post-Industrial Landscape Regeneration Design Along Jiangsu Canal from the Perspective of Cultural Creativity" in 2020 (Project number: 2020SJA0473); Phased research results of the second batch of industry-academy cooperation education project of the Ministry of Education in 2019(Project number: 201902294015)

\section{THE CONCEPT OF URBAN REGENERATION AND INDUSTRIAL HERITAGE}

In 1992, Ms. Lichfield of the London Planning Advisory Committee proposed in the article "For Urban Regeneration in the 1990s" that "urban regeneration" was summarized as a solution to urban problems through comprehensive and integrated propositions and actions as a guide, in order to explore the continuous improvement of economic, material environmental, social and natural environmental conditions in a region ${ }^{1}$. In July 2003, The International Committee for the Conservation of the Industrial Heritage (TICCIH) defined the scope of industrial heritage and clarified the value of industrial heritage through the Nizhny Tagil Charter (hereinafter referred to as Charter). The Charter states that industrial heritage is composed of the remnants of industrial culture and

1. Wu Chen. TOWARDS URBAN REGENERATION [J]. World Architecture, 2002 (12) 
possesses historical, technical, social, architectural and scientific values ${ }^{2}$.

\section{ANALYSIS OF THE STATUS QUO OF NANJING'S INDUSTRIAL HERITAGE PROTECTION}

\subsection{Historical Characteristics of Nanjing's Industrial Heritage}

Nanjing has the first batch of civilian and military industrial buildings in China. In the late Qing Dynasty (1840-1912), Li Hongzhang, the viceroy of Jiangnan Province and Jiangxi Province at that time, opened the Jiling Machine Mill. Nanjing became one of the origins of the Westernization Movement, and Jiling Machine Mill became the largest modern industry architectural complex in China. During the period of the Republic of China (1912-1949), due to convenient geographical advantages and railway transportation, urban infrastructure service facilities such as largescale power plants and water works were built during this period, and Nanjing became one of the more industrially developed cities in China. From the founding of New China to before the reform and opening up (1949-1978), Nanjing's urban master plan shifted the development of industrial areas that were originally concentrated in the urban area to independent industrial areas in the suburbs. After the reform and opening up (December 1978), Nanjing's industry has entered a period of all-round development, and new and large-scale expansion projects have been arranged in satellite towns. Later, due to the needs of urban development planning and ecological environmental protection, no new industrial land is added in the main urban area, and the industrial buildings in the urban area become the witness of industrial heritage and urban changes.

\subsection{Spatial Distribution Characteristics of Nanjing Industrial Heritage}

In the late Qing Dynasty (1840-1912), due to the convenient waterway transportation and superior geographical environment, the handicraft industry was mainly distributed along the banks of the Qin Huai River, thus forming the earliest industrial layout in Nanjing. During the period of the Republic of China (1912-1949), according to the "Capital Plan", the planning scope of the industrial zone was concentrated on both sides of the Yangtze River. After the founding of New China (after 1949), affected by the development of urbanization in China, newly-built industrial areas were constructed along both banks by taking advantage of the water transport conditions of the outer Qin Huai River and the Yangtze River. It can be seen from this that the distribution characteristics of Nanjing's industrial heritage include: First, it was built by searching for water, distributing from the inner Qin Huai River to the outer Qin Huai River, to the middle and lower reaches of the Yangtze River, which verified this view; second, it was built along the fringe of the city, which was related to factors such as lower land prices on the fringe of the city and also met the requirements of environmental protection. From the development of the late Qing Dynasty and the early Republic of China (1900-1920) to the present, it can be seen that in the overall urban planning of Nanjing, the establishment of industrial land is characterized by migration from the inside of the city to the outside of the city ("Figure 1").

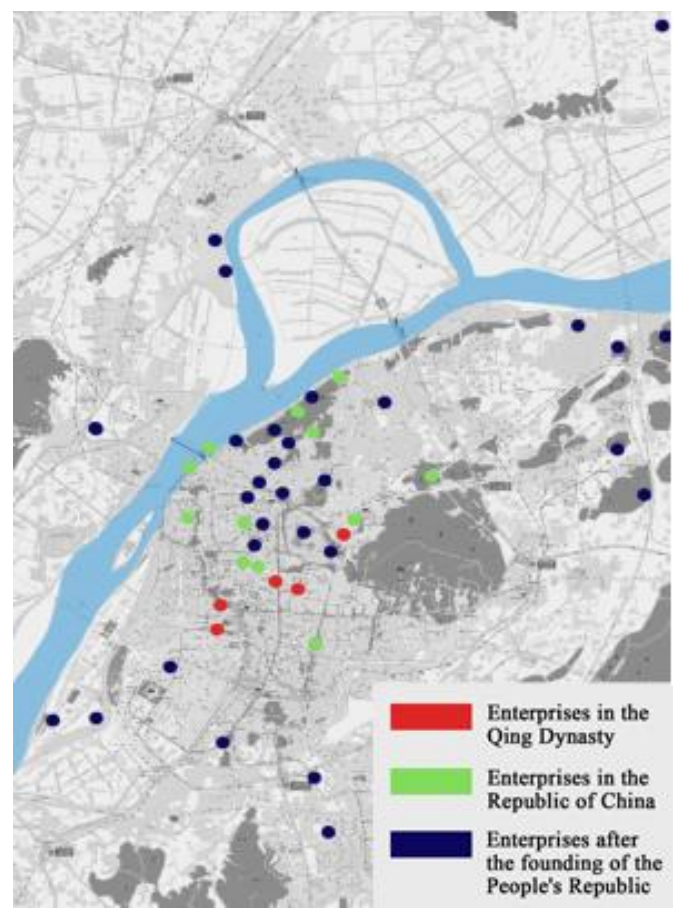

Figure 1 Spatial distribution characteristics of Nanjing's industrial heritage.

2. Wu Yao, Wang Wenjie. The expression of "authenticity" and "adaptability" in the reuse of industrial architectural heritage against the background of the new era[J]. Art Panorama, 2020 (03) 


\subsection{Type Characteristics of Nanjing Industrial Heritage}

Nanjing's industrial heritage buildings span a large age, including the late Qing Dynasty (18401912), the Republic of China (1912-1949), and after the founding of the People's Republic of China (1949). Among the 52 Nanjing industrial heritage sites announced, there are 5 industrial plants built in the late Qing Dynasty (1840-1912), 11 industrial plants built during the Republic of China (19121949), and 36 industrial plants established after the founding of the People's Republic of China (1949) [1]. The industrial heritage category is complete, with a total of 13 industry types, covering Nanjing Shipyard Ruins Park, which mainly focuses on the shipbuilding industry, etc., Inert Gas Plant, which mainly focuses on chemical industry, etc., Yeshan Iron Deposit, which mainly focuses on mining industry, etc., and Nanjing Brocade, which mainly focuses on weaving industry, etc., Jiangnan Cement Factory, which mainly focuses on the building materials industry, etc., P S Cassidy, which focuses on the food industry, etc., and water works and power plants focusing on municipal transportation facilities, etc. The industrial buildings in the industrial factory district are divided into four functions of production plant buildings, office management buildings, storage buildings and residential facility buildings due to their use functions.

\section{COUPLING RELATIONSHIP BETWEEN PROTECTION AND RENEWAL OF INDUSTRIAL HERITAGE AND URBAN REGENERATION}

\subsection{The Cultural Value of Industrial Heritage Meets the Spiritual Needs of Urban Regeneration}

"Urban regeneration" is a comprehensive improvement of the inner spiritual, cultural, social, economic and technological aspects of a city. As the material carrier of the development of human society, industrial heritage has a strong historical sense of scene atmosphere. While people obtain their own use requirements, they also obtain the opportunity to have a dialogue with history. This is in line with the instinctive pursuit of history and culture by the cultural industry-related industry main body, which has become an environmental scene that stimulates the inspiration of the creative main body and meets the spiritual needs of urban regeneration [2] ("Figure 2"). In the history of China, the industrial heritage of cities with concession history such as Shanghai, Qingdao and Tianjin are even more materialized witnesses of colonial history, telling the past and present of the city. Another example is that, for cities like Beijing, Shanxi, and Xi'an that had "Project 156" in the 1950 s, the industrial heritage built with the help of the former Soviet Union and the former nation of Germany has typical Soviet socialism and Bauhaus style. Therefore, the spiritual characteristics of the industrial heritage in various places also reflect the development process of urban cultural capital and economic capital.

\subsection{The Spatial Form of Industrial Heritage and Low-cost Rent Meet the Needs of the Creative Class}

Compared with other buildings, industrial buildings show stronger mechanical aesthetics. Industrial history and culture and special spatial forms endow the old industrial buildings with artistic characteristics. Among them, the most famous is the Soho Culture and Art District in the United States. In the 19th century, this area became the aggregated place of factories and industrial warehouse areas, and then gradually declined with the arrival of the post-industrial era in the United States. Soho District attracted a large number of pioneers in the cultural industry with its low rents. Individual art creators such as painters, designers, painting-sellers and musicians or small and medium-sized creative enterprises in the growth stage preferred the abandoned attics, spacious warehouses and tall factories in Soho. The special spatial composition of industrial buildings met the functional needs of artists' creations. In addition, the development characteristics of the industry required art creators to have a strong sensitivity and communication to cultural information and social frontiers, and be able to get in touch with the latest cultural trends earlier, so as to use this feature to better explore the place spirit of the industrial heritage. Therefore, the idle industrial buildings in the old industrial area of the city became the first choice of the cultural and creative class due to their low cost of use [3]. 


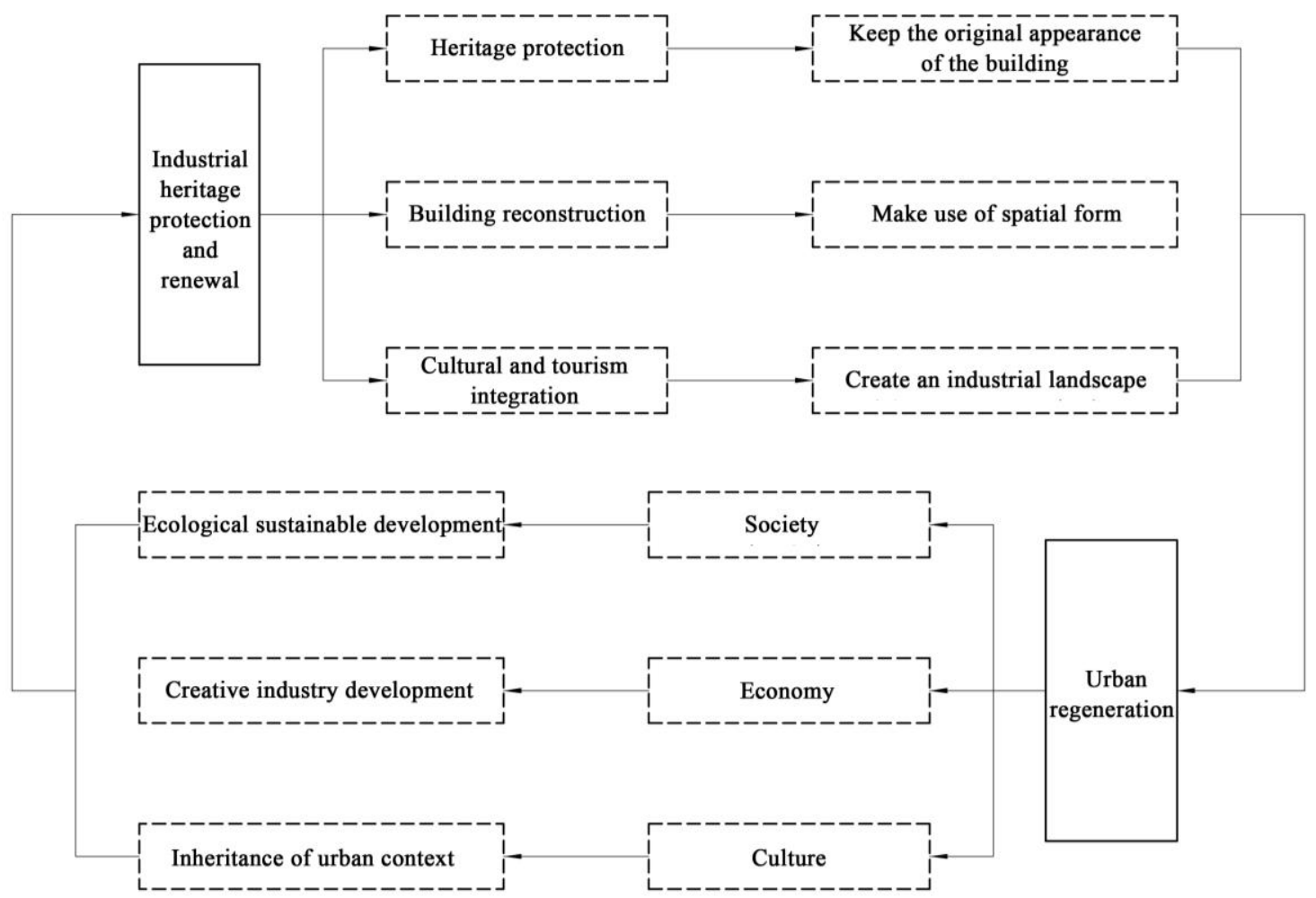

Figure 2 The relationship between the protection and renewal of industrial heritage and urban regeneration.

\subsection{Ecological Transformation of Industrial Heritage Promotes Sustainable Urban Development}

As the concept of ecological civilization construction has been paid more and more attention by the public, ecological environmental problems have become particularly prominent in the process of utilization and renewal of urban old industrial areas. Compared with other industrial buildings, industrial heritage has a special architectural style and historical value. When it is adaptively transformed and reused, raw materials should be used to protect its original architectural style as much as possible, so that it can reintegrate into the urban life of modern people, revive the regional characteristics and vitality of the city, and also play a positive role in protecting the ecological environment [3]. The transformation method of industrial heritage should not only start from the perspective of art, culture and green technology and focus on the systematic transformation of building functions and structures, but also build large-scale multi-functional comprehensive communities and develop creative industries and exhibition industries with low energy consumption and high output, etc. from the perspectives of urban planning and regional planning to realize work-life relevance, job-housing balance, reduce external traffic, promote a low-carbon economy and achieve sustainable urban development.

\section{PROTECTION AND RENEWAL STRATEGIES OF NANJING INDUSTRIAL HERITAGE}

\subsection{Integrating Industrial Heritage Land and Optimizing Urban Space}

In April 2017, Nanjing Urban Planning Bureau proposed in the "Nanjing Industrial Heritage Protection Plan": "The large-scale and important industrial heritage and ancillary facilities should be protected as a whole, and the sporadic industrial heritage can be protected in a mobile manner." 3 First of all, for the well-preserved industrial heritage located along arterial traffic, such as urban

3. Data source: Nanjing Bureau of Planning and Natural Resources, http://www.njghj.gov.cn 
streets and along the railways, the buildings and surrounding environment can be appropriately transformed without changing the overall environmental layout and architectural appearance, retaining historical and cultural characteristics, for example, the Jiling Machine Mill, which was transformed into a creative industry park, and the Capital Water Plant of the Republic of China, which was transformed into the Nanjing Tap Water History Exhibition Hall. Secondly, for the surrounding industrial heritages with superior ecological environment, such as the National Government Capital Power Plant on the north and south banks of the Yangtze River, along the outer Qin Huai River, P S Cassidy, and Nanjing Zhongshan Watch Factory in the Sifang City in Zijin Mountain, it is recommended to retain the industrial characteristics of the building complex and transform it into an urban public leisure space, so that the protection of industrial heritage can be integrated into modern urban life. Finally, because of its good natural ecological environment, the suburban industrial heritage far away from the city should be transformed into a large-scale industrial landscape park, such as the Liuhe Yeshan National Mine Park under planning and construction.

\subsection{Giving Full Play to the Regional Advantages of Industrial Heritage and Improving the Urban Public Service System}

For industrial heritage buildings with important historical value and great contributions to society, it is necessary to combine industrial sites, structures and industrial elements, and retain the original scene environment and production conditions. Through the display of industrial facilities and technological processes, the sense of history and reality of the industrial zone is once again presented. Its transformation and reuse model mainly includes theme museums, exhibition halls and memorial halls, etc., to enhance the public culture service function of industrial heritage and stimulate people's sense of place identity [5]. Most of Nanjing's industrial heritage buildings that have been replaced with museum and exhibition hall models are cultural heritage protection units with high remain value and need to be preserved as a whole or are excellent industrial heritage buildings.

\subsection{Exploiting the Spatial Potential of Industrial Heritage and Building a Cluster of Creative Industries}

With the adjustment of the industrial structure, the traditional manufacturing industry moves away from the urban center, instead, the creative industry develops rapidly. The government has played a leading, promoting, supporting and protecting role, formulating creative industry development strategies and related industrial policies, and integrating economy and culture. Through scientific and technological support and market-oriented operation, it can create valuable intelligent industries, thus promoting the clustering of creative industries. On the one hand, it shares resources and elements, on the other hand, it effectively reduces production costs, forming symbiotic and complementary effects and building a sustainable creative city through the establishment of cultural and creative industrial parks [6]. Therefore, the industrial heritage in the spatial structure just meets the high-space, large-scale and agglomeration effects required by the cultural and creative industries, and attracts high-quality creative industry personnel to gather here by creating a high-quality and changeable living environment, thereby promoting the exchange and collision of culture and information and finally accomplishing the goal of win-win economic benefit and cultural effect. The Window of the World Creative Industry Park in Nanjing was originally the No. 7 Radio Factory built in 1967. Relying on the planning and layout of the original plant in the plant area, it was transformed into a LOFT creative office based on the principle of maximum retention and reuse, deriving functional and rational and self-disciplined old plant to create a new industry development space.

\subsection{Using the Cultural Value of Industrial Heritage to Build a Compact Comprehensive Community}

The construction of a compact comprehensive community requires a large area with more buildings (groups) in the industrial heritage and concentrated construction in a large area. Such industrial heritage is generally located in the decline area of the old city. Due to the characteristics of high space and large span of industrial buildings, after unified planning and development, it should be transformed into a comprehensive community with multiple functions such as office, residence, commerce and 
entertainment ("Figure 3"). Nanjing Chenguang 1865 Creative Industry Park is a typical representative of this model. It was originally the Jiling Machine Mill, one of the four major arsenals in China in the late Qing Dynasty. The park is located on the east side of the land outside Zhonghua Gate in Nanjing. There are 9 old factories in the Qing Dynasty, 15 factories in the Republic of China, and 17 factories in the 1950s and 1960s. It borders the site of Daihouonji to the west and Qin Huai River to the north. It is the

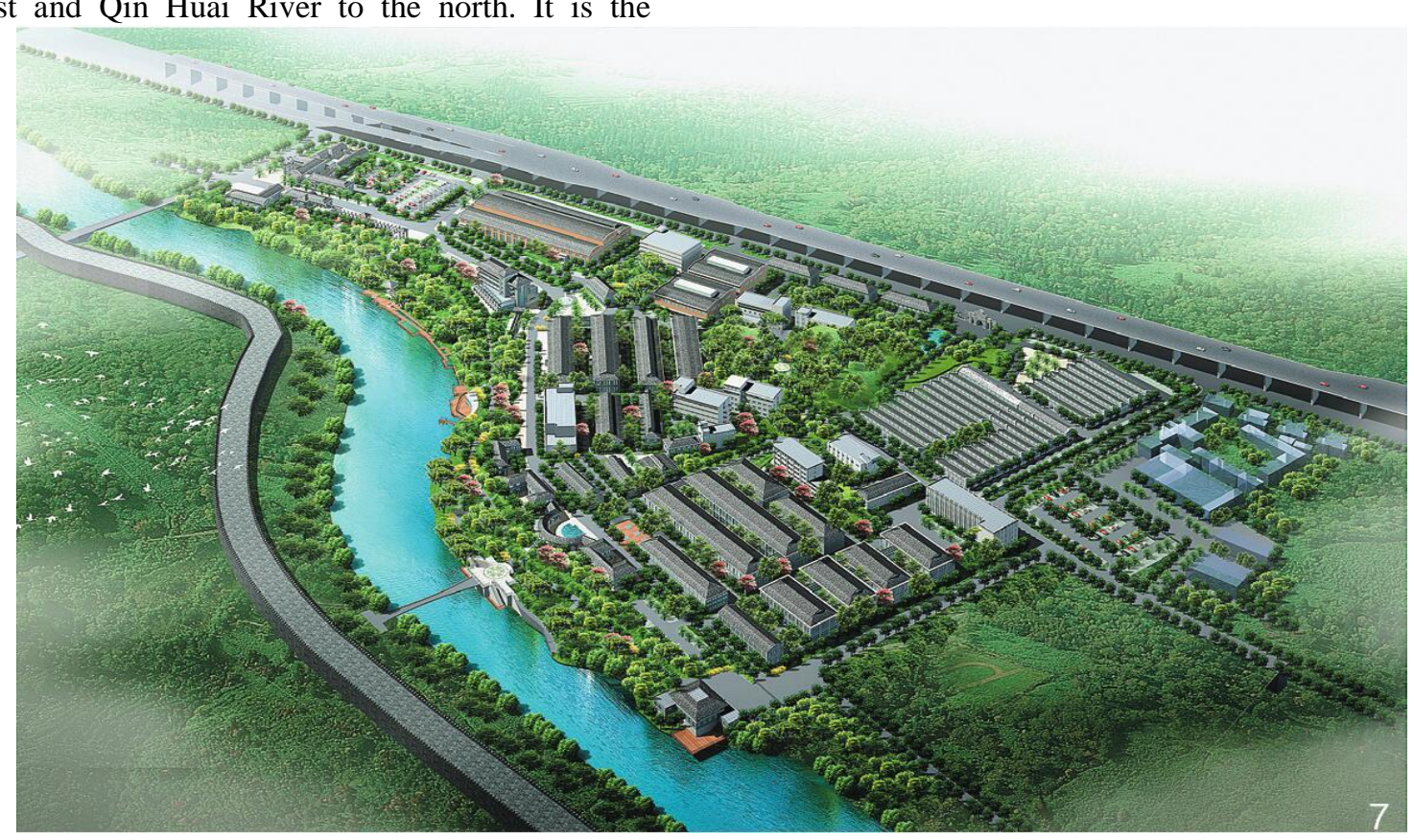

Figure 3 Aerial view of Jiling Machine Mill. largest modern industrial complex in China. The park is divided into 5 different functional areas: scientific and technological innovation research and development area, natural landscape display area, cultural and creative exhibition area, arts and crafts creation area, and tourism supporting service area ("Figure 4") [7]. At present, it has developed into a multi-functional comprehensive development community integrating science and technology, culture, tourism, and commerce. 


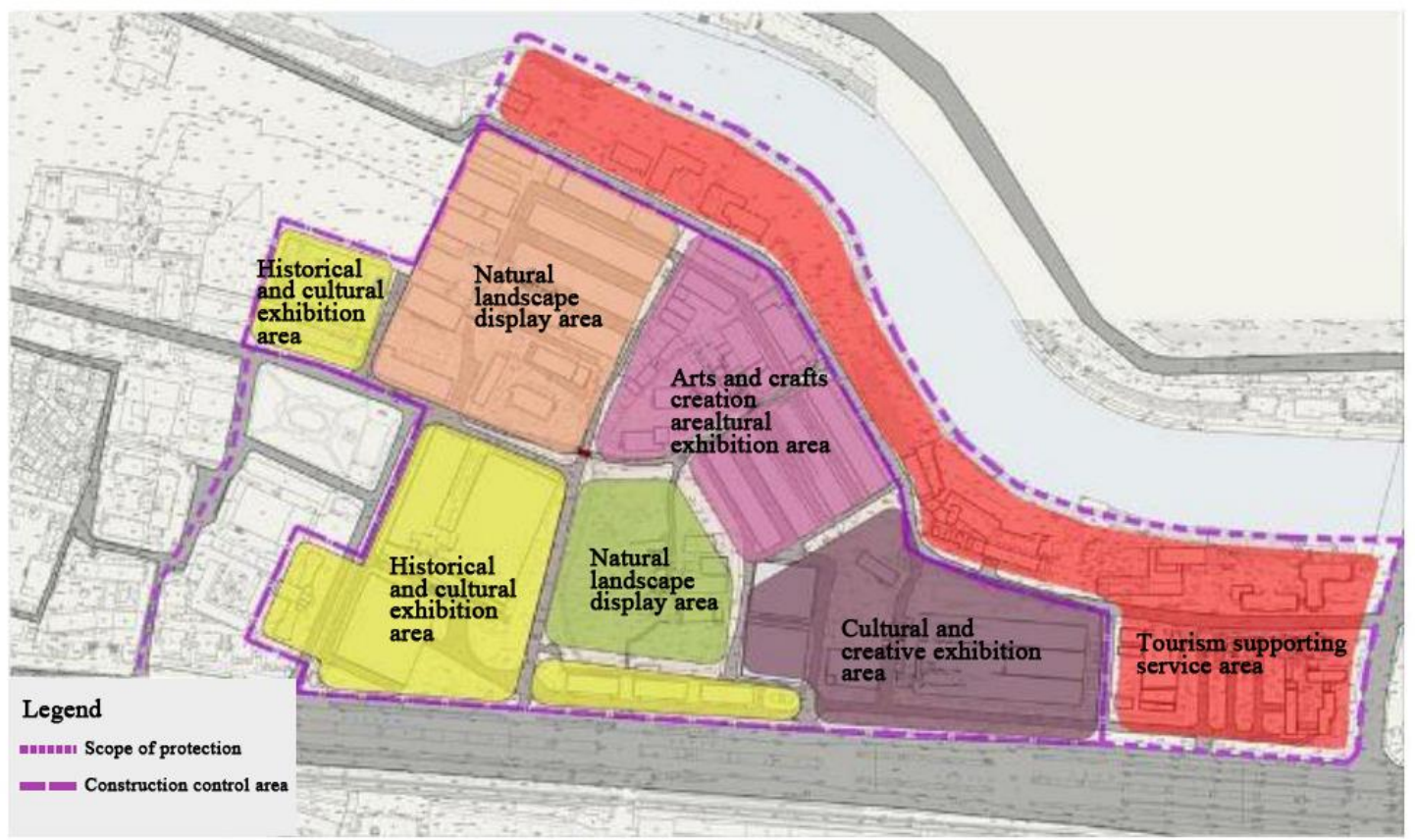

Figure 4 Schematic diagram of the functional planning of Jiling Machine Mill.

\subsection{Practicing the Concept of Green Development and Improving the Ecological Environment of Habitation}

The old industrial buildings have a certain degree of pollution to the natural environment in the process of construction and use due to their own particularities. Therefore, the governance and sustainable development of the ecological environment cannot be ignored in the process of industrial heritage transformation and utilization. On the premise of respecting the original site landscape environment, the principle of minimal intervention should be adopted on the site, and waste industrial materials, equipment and facilities, etc. should be integrated into the landscape environment design, thereby reducing the use of new resources, saving energy, and embodying the principle of sustainable development. Nanjing Hongshan Creative Factory Industrial Park was originally the Nanjing Construction Machinery Factory built in the 1960s. It makes full use of the current situation of the site in planning, provides people with rich space experience and landscape viewing opportunities through the combination of plants, structures, old machinery and equipment, and the environment, retains historical memory, revitalizes the site, and constructs a composite plant landscape community, which can be of positive significance to the restoration of the urban ecological environment.

\section{CONCLUSION}

The industrial heritage that carries the industrial civilization is becoming an industrial cultural heritage of specific value with the passage and accumulation of history, and is an important part of urban regeneration. By analyzing the relationship between the protection and renewal of industrial heritage and urban regeneration, this article fully explores the value of industrial heritage in spiritual, cultural, social, economic and technological aspects, and proposes strategies for the protection and renewal of Nanjing's industrial heritage based on urban regeneration. In the process of urban regeneration, the protection and renewal of industrial heritage has played an engine role, effectively improving the city's service functions, enhancing the sense of historical massiness of the city, inheriting the historical context of the city, and providing an opportunity for the shaping of the characteristics of the place and the regeneration of the city.

\section{AUTHORS' CONTRIBUTIONS}

Jingjing $\mathrm{Xu}$ is responsible for the writing and research, Lei Jiang is responsible for the 
modification, and Junjin Qian is responsible for data collection.

\section{REFERENCES}

[1] Xu Yanping, Xu Longmei. Nanjing Industrial Heritage [M]. Nanjing: Nanjing Press, 2012. (in Chinese)

[2] Liu Boying, Feng Zhongping. Urban Industrial Land Renewal and Industrial Heritage Protection [M]. Beijing: China Building Industry Press, 2009. (in Chinese)

[3] Sun Miao. Research on Adaptability Strategies of Urban Industrial Heritage Transformation Communities under the Global Urban Background [J]. Industrial building, 2018(07)

[4] Shan Jixiang. From the protection of cultural relics to the protection of cultural heritage Urban Industrial Land Renewal and Industrial Heritage Protection [M]. Tianjin: Tianjin University Press, 2019. (in Chinese)

[5] Zeng Rui. Research on Industrial Heritage Renewal Based on Conservation Transformation and Regeneration Evaluation [D]. Hefei University of Technology, 2018(21)

[6] Wang Bo, Ren Wenlong. Research on Protection and Regeneration of Industrial Heritage in Jiangsu Province [J]. Jiangsu Social Sciences, 2021 (09). (in Chinese)

[7] Gongkai, Ji Yinglei. Investigation and Research on the Reconstruction of Nanjing Industrial Architecture Heritage - - Taking 1865 Creative Industry Park as an example [J]. Architecture Journal, 2010(12) 